\title{
Comment
}

\section{The potential science and engineering value of samples delivered to Earth by Mars sample return}

International MSR Objectives and Samples Team (iMOST), D. W. BEATY ${ }^{1}$, M. M. GRADY ${ }^{2}$, H. Y. MCSWEEN (iD ${ }^{3 *}$, E. SEFTON-NASH ${ }^{4}$, B. L. CARRIER ${ }^{1}$, F. ALTIERI ${ }^{5}$, Y. AMELIN ${ }^{6}$, E. AMMANNITO ${ }^{7}$, M. ANAND ${ }^{2}$, L. G. BENNING ${ }^{8}$, J. L. BISHOP ${ }^{9}$, L. E. BORG ${ }^{10}$, D. BOUCHER ${ }^{11}$, J. R. BRUCATO ${ }^{12}$, H. BUSEMANN ${ }^{13}$, K. A. CAMPBELL ${ }^{14}$, A. D. CZAJA ${ }^{15}$, V. DEBAILLE ${ }^{16}$, D. J. DES MARAIS ${ }^{17}$, M. DIXON ${ }^{18}$, B. L. EHLMANN ${ }^{19}$, J. D. FARMER ${ }^{20}$, D. C. FERNANDEZ-REMOLAR ${ }^{21}$, J. FILIBERTO ${ }^{22}$, J. FOGARTY ${ }^{23}$, D. P. GLAVIN ${ }^{24}$, Y. S. GOREVA ${ }^{1}$, L. J. HALLIS ${ }^{25}$, A. D. HARRINGTON ${ }^{23}$, E. M. HAUSRATH ${ }^{26}$, C. D. K. HERD ${ }^{27}$, B. HORGAN ${ }^{28}$, M. HUMANYUN ${ }^{29}$, T. KLEINE ${ }^{30}$, J. KLEINHENZ ${ }^{31}$, R. MACKELPRANG ${ }^{32}$, N. MANGOLD ${ }^{33}$, L. E. MAYHEW ${ }^{34}$, J. T. MCCOY ${ }^{23}$, F. M. MCCUBBIN ${ }^{23}$, S. M. MCLENNAN ${ }^{35}$, D. E. MOSER ${ }^{36}$, F. MOYNIER ${ }^{37}$, J. F. MUSTARD ${ }^{38}$, P. B. NILES ${ }^{23}$, G. G. ORI ${ }^{39}$, F. RAULIN ${ }^{40}$, P. RETTBERG ${ }^{41}$, M. A. RUCKER ${ }^{23}$, N. SCHMITZ ${ }^{41}$, S. P. SCHWENZER ${ }^{2}$, M. A. SEPHTON ${ }^{42}$, R. SHAHEEN ${ }^{43}$, Z. D. SHARP ${ }^{44}$, D. L. SCHUSTER ${ }^{45}$, S. SILJESTROM ${ }^{46}$, C. L. SMITH ${ }^{47}$, J. A. SPRY ${ }^{9}$, A. STEELE $^{48}$, T. D. SWINDLE ${ }^{49}$, I. L. TEN KATE ${ }^{50}$, N. J. TOSCA ${ }^{51}$, T. USUI ${ }^{52}$, M. J. VAN KRANENDONK ${ }^{53}$, M. WADHWA ${ }^{20}$, B. P. WEISS ${ }^{54}$, S. C. WERNER ${ }^{55}$, F. WESTALL ${ }^{56}$, R. M. WHEELER ${ }^{57}$, J. ZIPFEL ${ }^{58}$, and M. P. ZORZANO ${ }^{59}$

\footnotetext{
${ }^{1}$ Jet Propulsion Laboratory, California Institute of Technology

${ }^{2}$ Open University

${ }^{3}$ University of Tennessee ${ }^{4}$ ESTEC 


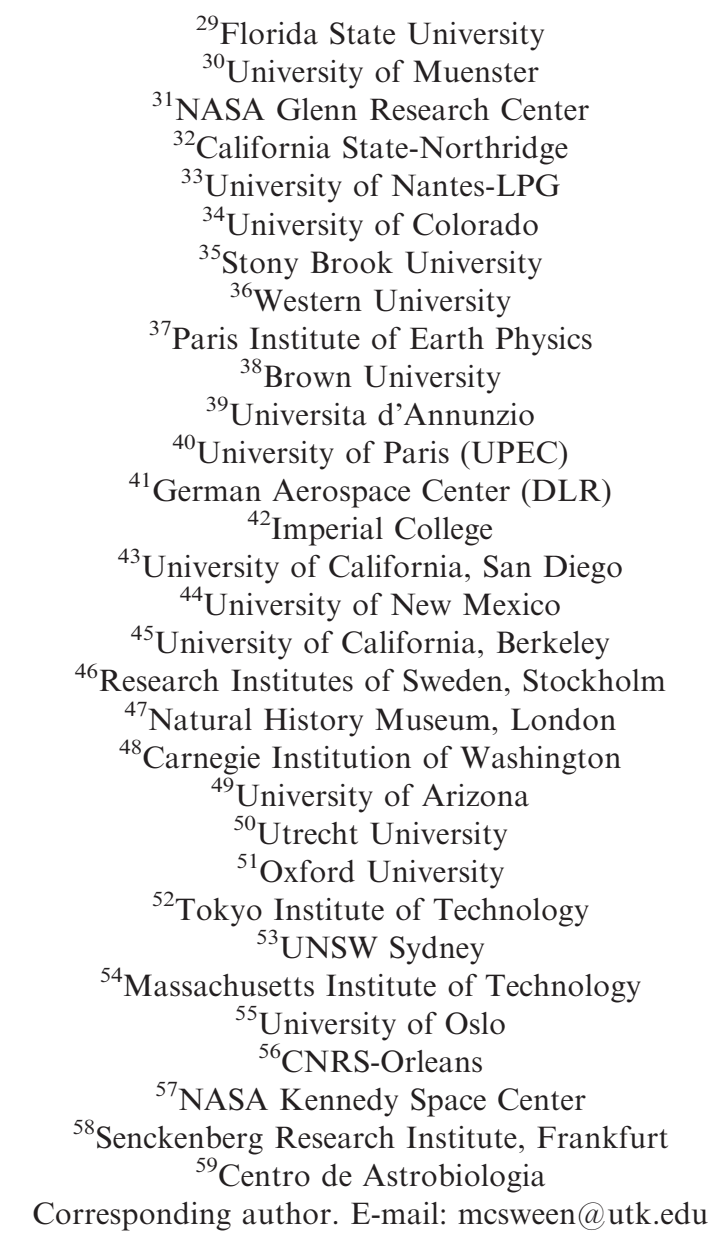

(Received 02 October 2018; revision accepted 23 November 2018)

Abstract-Executive summary provided in lieu of abstract.

\section{CONTEXT FOR THE IMOST REPORT}

Return of samples from the surface of Mars has been a goal of the international Mars science community for many years. Strategies for the collection of such samples have ranged from "grab and go" acquisition from the surface, to dust collection in the atmosphere, to scientific selection by geologically capable rovers. As comprehension of the complexity and potential habitability of Mars has increased, so has the realization that a randomly collected sample, while potentially interesting, would not be sufficient to answer the really big questions that for years have motivated Mars surface sample return. The deployment of NASA's Mars 2020 (M-2020) samplecollecting rover has brought the issues associated with the completion of Mars sample return (MSR) into sharp focus. M-2020 will collect and cache geological samples for possible eventual return to Earth. The transportation to Earth would require a sample-retrieval mission, which could also collect atmospheric samples, and an Earthreturn mission. Involvement of the international community in these missions would be very beneficial in terms of sharing cost, risk, and benefit.

In 2017, the space exploration programs associated with the International Mars Exploration Working Group (IMEWG) began discussion of a formal program of cooperation and collaboration among space-faring nations related to MSR. As input to this, the international MSR Objectives and Samples Team (iMOST) was chartered by IMEWG to address key science planning questions.

The purpose of the study was to update the scientific and engineering value of MSR, given the nowknown realities of the M-2020 sampling system; the incremental discoveries from Mars that have been made since the last significant MSR study; and evolving priorities in astrobiology, geology, and geochemistry. 
The iMOST team has re-evaluated and updated the sample-related science and engineering objectives of a MSR campaign. The iMOST team has also undertaken to define the measurements and the types of samples that can best address the objectives.

The extraterrestrial samples community is among the natural audiences for the iMOST report by virtue of the fact that they will analyze the returned samples. The intent of the report is also to convey information in support of the following:

- Planning processes for the potential MSR retrieval and transportation missions: We have updated our understanding of the scientific and engineering value of the M-2020 samples if they were returned to Earth, to assess whether or not their value justifies the cost.

- Sample acquisition: Some of the scientific objectives of MSR require certain types of samples, or sample suites. The report conveys the relationships between samples and objectives to the M-2020 science team, for use as they plan surface operations and select the samples to be collected.

- Sample return: The M-2020 rover has more sample tubes than are intended to be returned. In that case, some future team associated with the retrieval missions will make decisions about which samples to return. This report may help provide the technical basis for those decisions.

- Sample curation and analysis: The report is aimed at supporting planning for the curation needed to preserve the samples and instrumental facilities required to make the measurements associated with achieving the objectives of MSR.

The report is presented in full as an electronic-only publication of Meteoritics \& Planetary Science, available at https://doi.org/10.1111/maps.13242. What follows is an outline of the report and its findings.

\section{SUMMARY OF OBJECTIVES AND SUB- OBJECTIVES FOR MSR IDENTIFIED BY IMOST}

Seven objectives have been defined for MSR, traceable through two decades of previously published international priorities. The first two objectives are further divided into subobjectives. Within the main part of the iMOST report, the importance to science and/or engineering of each objective is described, critical measurements that would address the objectives are specified, and the kinds of samples that would be most likely to carry key information are identified. These seven objectives provide a framework for demonstrating how the first set of returned Martian samples would impact future Martian science and exploration. They also have implications for how analogous investigations might be conducted for samples returned by future missions from other solar system bodies, especially those that may harbor biologically relevant or sensitive material, such as Ocean Worlds (Europa, Enceladus, Titan) and others.

Objective 1: Interpret the primary geologic processes and history that formed the Martian geologic record, with an emphasis on the role of water.

Intent: To investigate the geologic environment(s) represented at the Mars 2020 landing site, provide definitive geologic context for collected samples, and detail any characteristics that might relate to past biologic processes.

This objective is divided into five subobjectives that would apply at different landing sites.

1.1. Characterize the essential stratigraphic, sedimentologic, and facies variations of a sequence of Martian sedimentary rocks.

Intent: To understand the preserved Martian sedimentary record.

Samples: A suite of sedimentary rocks that span the range of variation.

Importance: Basic inputs into the history of water, climate change, and the possibility of life.

1.2. Understand an ancient Martian hydrothermal system through study of its mineralization products and morphological expression.

Intent: To evaluate at least one potentially life-bearing "habitable" environment.

Samples: A suite of rocks formed and/or altered by hydrothermal fluids.

Importance: Identification of a potentially habitable geochemical environment with high preservation potential.

1.3. Understand the rocks and minerals representative of a deep subsurface groundwater environment.

Intent: To evaluate definitively the role of water in the subsurface.

Samples: Suites of rocks/veins representing water/rock interaction in the subsurface.

Importance: May constitute the longest lived habitable environments and a key to the hydrologic cycle.

1.4. Understand water/rock/atmosphere interactions at the Martian surface and how they have changed with time.

Intent: To constrain time-variable factors necessary to preserve records of microbial life. Samples: Regolith, paleosols, and evaporites. Importance: Subaerial near-surface processes could support and preserve microbial life. 


\subsection{Determine the petrogenesis of Martian igneous} rocks in time and space.

Intent: To provide definitive characterization of igneous rocks on Mars.

Samples: Diverse suites of ancient igneous rocks.

Importance: Thermochemical record of the planet and nature of the interior.

Objective 2: Assess and interpret the potential biological history of Mars, including assaying returned samples for the evidence of life.

Intent: To investigate the nature and extent of Martian habitability, the conditions and processes that supported or challenged life, how different environments might have influenced the preservation of biosignatures and created nonbiological "mimics," and to look for biosignatures of past or present life.

This objective has three subobjectives:

2.1. Assess and characterize carbon, including possible organic and prebiotic chemistry.

Samples: All samples collected as part of Objective 1.

Importance: Any biologic molecular scaffolding on Mars would likely be carbonbased.

2.2. Assay for the presence of biosignatures of past life at sites that hosted habitable environments and could have preserved any biosignatures.

Samples: All samples collected as part of Objective 1.

Importance: Provides the means of discovering ancient life.

2.3. Assess the possibility that any life forms detected are alive, or were recently alive.

Samples: All samples collected as part of Objective 1.

Importance: Planetary protection, and arguably the most important scientific discovery possible.

Objective 3: Quantitatively determine the evolutionary timeline of Mars.

Intent: To provide a radioisotope-based time scale for major events, including magmatic, tectonic, fluvial, and impact events, and the formation of major sedimentary deposits and geomorphological features.

Samples: Ancient igneous rocks that bound critical stratigraphic intervals or correlate with crater-dated surfaces.

Importance: Quantification of Martian geologic history.

Objective 4: Constrain the inventory of Martian volatiles as a function of geologic time and determine the ways in which these volatiles have interacted with Mars as a geologic system.
Intent: To recognize and quantify the major roles that volatiles (in the atmosphere and in the hydrosphere) play in Martian geologic and possibly biologic evolution.

Samples: Current atmospheric gas, ancient atmospheric gas trapped in older rocks, and minerals that equilibrated with the ancient atmosphere.

Importance: Key to understanding climate and environmental evolution.

Objective 5: Reconstruct the processes that have affected the origin and modification of the interior, including the crust, mantle, core, and the evolution of the Martian dynamo.

Intent: To quantify processes that have shaped the planet's crust and underlying structure, including planetary differentiation, core segregation and state of the magnetic dynamo, and cratering.

Samples: Igneous, potentially magnetized rocks (both igneous and sedimentary) and impactgenerated samples.

Importance: Elucidate fundamental processes for comparative planetology.

Objective 6: Understand and quantify the potential Martian environmental hazards to future human exploration and the terrestrial biosphere.

Intent: To define and mitigate an array of health risks related to the Martian environment associated with the potential future human exploration of Mars.

Samples: Fine-grained dust and regolith samples.

Importance: Key input to planetary protection planning and astronaut health.

Objective 7: Evaluate the type and distribution of in situ resources to support potential future Mars exploration.

Intent: To quantify the potential for obtaining Martian resources, including use of Martian materials as a source of water for human consumption, fuel production, building fabrication, and agriculture.

Samples: Regolith.

Importance: Production of simulants that will facilitate long-term human presence on Mars.

\section{SUMMARY OF IMOST FINDINGS}

Several specific findings were identified during the iMOST study. While they are not explicit recommendations, we suggest that they should serve as guidelines for future decision making regarding planning of potential future MSR missions.

1. The samples to be collected by the Mars 2020 (M2020) rover will be of sufficient size and quality to address and solve a wide variety of scientific questions. 
2. Samples, by definition, are a statistical representation of a larger entity. Our ability to interpret the source geologic units and processes by studying sample subsets is highly dependent on the quality of the sample context. In the case of the M-2020 samples, the context is expected to be excellent, and at multiple scales. (A) Regional and planetary context will be established by the ongoing work of the multiagency fleet of Mars orbiters. (B) Local context at field area, outcrop, hand sample, and hand lens scales will be established using the instruments carried by M-2020.

3. A significant fraction of the value of the MSR sample collection would come from its organization into sample suites, which are small groupings of samples designed to represent key aspects of geologic or geochemical variation.

4. If the Mars 2020 rover acquires a scientifically wellchosen set of samples, with sufficient geological diversity, and if those samples were returned to Earth, then major progress can be expected on all seven of the objectives proposed in this study, regardless of the final choice of landing site. The specifics of which parts of Objective 1 could be achieved would be different at each of the final three candidate landing sites, but some combination of critically important progress could be made at any of them.

5. An aspect of the search for evidence of life is that we do not know in advance how evidence for Martian life would be preserved in the geologic record. In order for the returned samples to be most useful for both understanding geologic processes (Objective 1) and the search for life (Objective 2), the sample collection should contain both typical and unusual samples from the rock units explored. This consideration should be incorporated into sample selection and the design of the suites.

6. The retrieval missions of a MSR campaign should (1) minimize stray magnetic fields to which the samples would be exposed and carry a magnetic witness plate to record exposure, (2) collect and return atmospheric gas sample(s), and (3) collect additional dust and/or regolith sample mass if possible.

Editorial Handling - Dr. A. J. Timothy Jull 